\title{
Effects of walnut intake on blood pressure: A systematic reviewand meta-analysis of randomized controlled trials
}

\author{
Jiayang Li' | Bo Jiang ${ }^{2} \mid$ Heitor O. Santos ${ }^{3}$ | Dinamene Santos ${ }^{4}$ | Ambrish Singh ${ }^{5}$ | Lei Wang ${ }^{2}$
}

'Drug Clinical Trial Institution, The Affiliated Hospital of Zunyi Medical University, Zunyi, China

${ }^{2}$ Department of Vascular Surgery, First Hospital of China Medical University Key Laboratory of Pathogenesis, Prevention and Therapeutics of Aortic Aneurysm, Shenyang, China

${ }^{3}$ School of Medicine, University of Uberlandia (UFU), Uberlandia, Brazil

${ }^{4}$ East Sussex Healthcare NHSTrust, Conquest Hospital, St Leonards-On-Sea, UK

${ }^{5}$ Menzies Institute for Medical Research, University of Tasmania, Hobart, Australia

Correspondence

Lei Wang, Department of Vascular Surgery, First Hospital of China Medical University, Key Laboratory of Pathogenesis, Prevention and Therapeutics of Aortic Aneurysm, Liaoning Province, 155\# Nanjingbei Street, Shenyang, 110001, China.

Email: wanglei@cmu.edu.cn

\begin{abstract}
The impact of walnuts on blood pressure (BP) is not a well-established fact. Although several studies have assessed the effects of walnut consumption on BP, results are conflicting. Thus, we examined the effects of walnut doses and length of supplementation on BP. Biomedical databases were searched for published trials that compared walnutenhanced diet to control diet. Eighteen trials met eligibility criteria $(n=1,799)$. Overall, walnut consumption neither did alter SBP (weighted mean difference [WMD]: 0.08 mmHg; $95 \% \mathrm{Cl}:-0.69,0.85$ ) nor DBP (WMD: $0.08 \mathrm{Cl}$ : $-0.26,0.42$ ). In subgroup analyses, walnut ingestion $\leq 40 \mathrm{~g}$ was statistically correlated with reduction in SBP (WMD: $-0.53 \mathrm{mmHg}, 95 \% \mathrm{Cl}:-0.79,-0.26$ ) and DBP (WMD: $-0.191 \mathrm{mmHg}, 95 \% \mathrm{Cl}:-0.384$, -0.034 ). Moreover, the length of intervention $\geq 8$ weeks was linked to a significant reduction in SBP (WMD: $-1.18 \mathrm{mmHg}, 95 \% \mathrm{Cl}:-1.30,-1.06$ ). Following dose-response evaluation, walnut intake significantly changed SBP $(p=.015)$ and DBP $(p=.026)$ through a nonlinear fashion at walnut dose up to $40 \mathrm{~g} / \mathrm{d}$. Nevertheless, these statistical results cannot be translated into clinical practice, once the changes expressed as WMD are slight taking into consideration the absolute values of BP categories. In conclusion, this meta- analysis does not support walnut consumption as a BP-lowering strategy.

\section{KE YWOR DS}

blood pressure, cardiovascular risk, diastolic blood pressure, meta-analysis, systolic blood pressure, walnut
\end{abstract}

\section{1 | INTRODUCTION}

Hypertension or high blood pressure (BP) is a key modifiable risk factor for cardiovascular diseases (CVD), hence being the main cause of global morbidity and mortality (Bochud, Marques-Vidal, Burnier, \& Paccaud, 2011; Forouzanfar et al., 2016; Lawes, Vander Hoorn, \& Rodgers, 2008). Around $40 \%$ of the global population has raised BP and the global burden of hypertension is estimated to exceed 1.6 billion by 2025 (Egan, Kjeldsen, Grassi, Esler, \& Mancia, 2019), leading to a subsequent increase in disability-adjusted life years and deaths related to hypertension (Forouzanfar et al., 2017). Furthermore, the economic burden of hypertension is another challenge, with estimated

Jiayang Li and Bo Jiang contributed equally to this work. medical cost attributed to high BP of approximately $\$ 51.2$ billion a year in the United States (Benjamin et al., 2017).

Among the adult population, an optimal BP level is defined as less than $120 / 80 \mathrm{mmHg}$, forecasting a lower risk of adverse cardiovascular events (Whelton, Carey, \& Aronow, 2018). Lifestyle modification along with healthy dietary interventions, such as engagement in physical and/or exercise activity, body weight control, reduced alcohol, and salt intake, diets rich in fruits and vegetables, and low-fat dairy products are well-known nonpharmacological approaches for improving BP control (Appel et al., 2006; Whelton et al., 2002). Over the years, a particular interest has grown in the role of nutrition and its impact on BP (Appel et al., 1997; Appel et al., 2005). Accordingly, Dietary Approaches to Stop Hypertension (DASH) is a healthy eating plan developed by National Heart, Lung, and Blood Institute (NHLBI) to 
help control elevated BP without medications (NIH, 2018). Along with fruits, vegetables and other prescribed healthiest foodstuffs, the DASH includes 1 serving per day of nuts (Challa, Tadi, \& Uppaluri, 2020), which are dietary components associated with improvement in cardiovascular healthy, as evidenced in meta-analyses (Del Gobbo, Falk, Feldman, Lewis, \& Mozaffarian, 2015; Mejia et al., 2014).

Walnut, a nut from any tree of genus Juglans, is a rich source of antioxidants, phytosterols, dietary fibers, protein, and fat, especially polyunsaturated fatty acids (PUFA), such as the $\alpha$-linolenic acid (ALA)/ omega-3 (n-3) (Kris-Etherton, Hu, Ros, \& Sabaté, 2008; Orsavova, Misurcova, Ambrozova, Vicha, \& Mlcek, 2015; Souza, Gomes, Naves, \& Mota, 2015). Compared to other nuts and vegetable oils, mainly those with a high monounsaturated fatty acids (MUFA) content, walnut contains a greater amount and types of polyphenolic compounds ( $\mathrm{Li}$, Tsao, Yang, Kramer, \& Hernandez, 2007).

Many studies have evaluated the effects of walnut-enriched diet on different metabolic parameters, such as total cholesterol (Morgan et al., 2002), low-density lipoprotein cholesterol (LDL-C) (Wu et al., 2014), BP (Del Gobbo et al., 2015), and vascular function (Del Gobbo et al., 2015). Despite a considerable body of evidence on the effect of walnut intake on cardiovascular health (Banel \& Hu, 2009; Din et al., 2011; Ma et al., 2010; Ros et al., 2004), it is unclear whether walnut consumption, per se, is a useful tool for controlling or lowering BP. We therefore performed a meta-analysis of randomized clinical trials (RCTs) to examine the overall impact of walnut consumption on both diastolic and systolic BP values, working on doses and length of intervention in order to translate the findings into a clinical conclusion.

\section{2 | METHODS}

\section{1 | Design}

A systematic review and meta-analysis was performed in accordance with the Preferred Reporting Items for Systematic Reviews and MetaAnalyses (PRISMA) statement (Moher, Liberati, Tetzlaff, Altman, \& Group, 2009).

\subsection{Search strategy}

We searched four databases including PubMed/Medline, Scopus, Web of sciences, and Google Scholar to identify articles that examined the effects of walnut intake on SBP and DBP, whose search strategy was conducted from inception up to April, 2020. The search process was performed using a combination of following keywords and medical subject headings (MeSH) terms: ("walnut” OR “walnuts” OR "juglans”) AND ("blood pressure" OR "systolic blood pressure" OR "diastolic blood pressure” OR “SBP” OR “DBP” OR "hypertension”) AND (“clinical trials” OR “clinical trial” OR “cross-over studies” OR “double-blind method" OR "single-blind method" OR "random allocation" OR "RCT" OR "random" OR “randomly" OR “placebo" $O R$ “assignment” $O R$ "intervention studies" OR "intervention" OR “controlled trial” OR "randomized” OR "Trial”
OR "randomised"). Moreover, we undertook an explicit hand-searching for all reference lists to find additional relevant articles that may have been dropped from initial search.

\section{3 | Selection criteria}

We considered studies that: (a) were employed in a randomized controlled design; (b) reported BP measurements at the baseline and at the end of the study for both walnut and control groups; (c) were conducted on adults. We excluded articles if: (a) the study was conducted on children, pregnant women or animals; (b) without a control group; (c) BP data havenot been reported; (d) reported duplicate data (i.e., BP values reported from the same study in two or more publications); (e) walnut intake combined with some medications, supplements and other nuts; (f) the study was not published in a peer-reviewed journal (conference papers, dissertations, and protocols).

\section{4 | Data extraction}

The required data from each of the selected studies were extracted independently by two investigators. A third, senior meta-researcher, was involved to discuss and resolve any disagreements. Following data were extracted from each of the studies: study design, the first author's surname, publication year, country, sample size, gender, participants' mean age, treatment duration, type of intervention, dose of walnut (g/day), health status, type of control, and results of BP. In addition, we contacted the corresponding authors in case of missing data or need for additional information for a specific study.

\subsection{Qualityassessment}

Cochrane scoring system was used to assess the methodological quality and risk of bias in the included studies (Moher et al., 2009). This tool includes domains working on: possible sources of bias in RCTs, including the random sequence generation; allocation concealment conditions; awareness of the allocated intervention; blinding of outcome assessment; incomplete outcome data; selective reporting; and other biases. Domains were classified as "high risk," "low risk," or "unclear." We categorized each publication as having poor, fair, or good quality, according to the Agency for Healthcare Research and Quality (AHRQ) standards. Publications were judged to be of poor quality if the allocation concealment conditions, random sequence generation, and blinding status reveal unclear or at high risk of bias.

\section{6 | Data synthesis and statisticalanalysis}

We used the STATA software (version 14) to perform the meta-analysis. The investigators extracted the mean and SD of SBP/DBP at the baseline and at end of the studies in both intervention and control 
groups. Upon data not obtained, the mean difference was derived by standard calculations. If mean $( \pm S D)$ of SBP/DBP was not directly presented and a standard error of the mean (SEM) was accessible instead of $S D$, we used the conversion to $S D$ through this formula: $S D^{1 / 4 S E M_{-}} n$, being " $n$ " the number of participants in each group. When no $S D$ s were described for net alteration in BP, the following formula was applied: $S D_{\text {alteration }}=$ square root $\left[\left(S D_{\text {pre-intervention }}\right) 2 \mathrm{P}\right.$ $\left(S D_{\text {post-intervention }}\right)$ 2_(2_R_SD pre-intervention_S $\left.\left.D_{\text {post-intervention }}\right)\right]$

(Higgins, 2011; Hozo, Djulbegovic, \& Hozo, 2005).

Random-effects model developed by Der Simonian was used in order to estimate effect sizes, with values represented by weighted mean difference (WMD) and 95\% confidence interval (CI). Employing in $l^{2}$ statistic, we quantified heterogeneity in the meta-analyses, with values greater than $50 \%$ revealing high level. A priori subgroup analysis of doses, duration of intervention, and healthy status was executed to identify potential sources of heterogeneity.

Nonlinear potential effects of walnut doses (g/day) and duration (weeks) of intervention were assessed by fractional polynomial modeling (Fan, 2018). Sensitivity analysis was also accomplished to investigate the extent of individual study interference using the leave-one-out method. Publication bias was evaluated by means of visual calculation of funnel plots and Egger's tests (Egger, Smith, Schneider, \& Minder, 1997).

\section{3 | RESULTS}

\section{1 | Study selection}

Initial database search returned 156 articles and, after removing duplicates, 97 articles remained. Afterscreening titles and abstracts, 72 articles were removed and 25 were yielded for full-text review. Finally, 17 articles with 18 comparisons were included in this meta-analysis (Figure 1).

\subsection{Characteristics of theincluded studies}

Although we firstly worked on a comprehensive search from inception up to April, 2020, the included studies were published coincidently

FIG URE 1 Flow chart for study examined

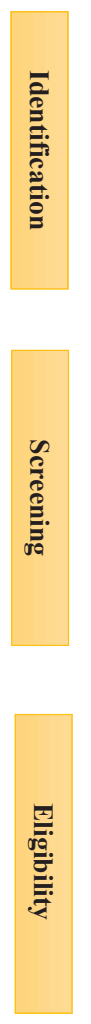
and included into the meta-analysis

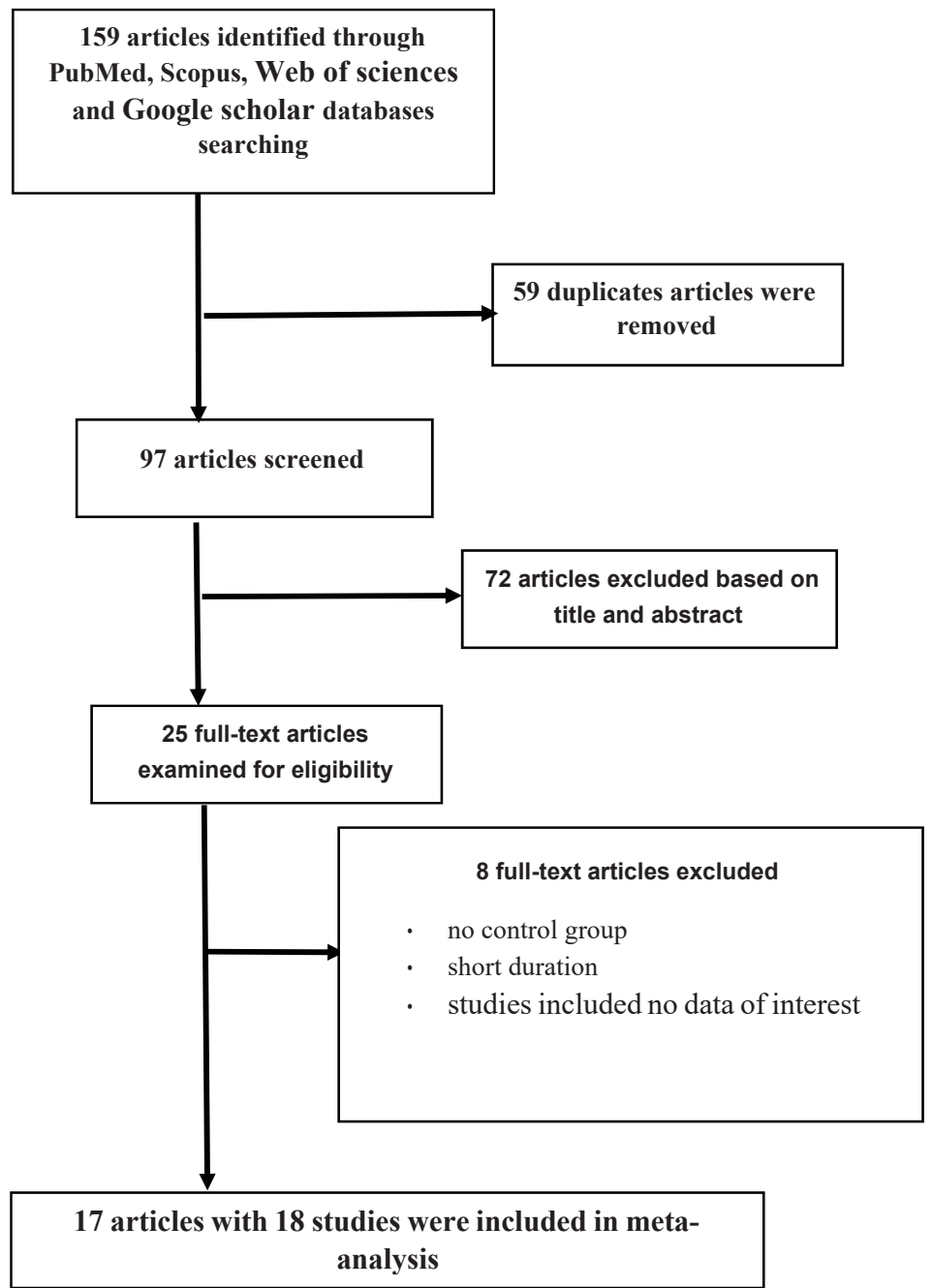


between 2004 and 2020. In general, studies before 2004 did not provide adequate data for our analyses. Studies were conducted in the United States (Al Abdrabalnabi et al., 2020; Katz et al., 2012; Ma et al., 2010; Njike, Ayettey, Petraro, Treu, \& Katz, 2015; Rock, Flatt, Barkai, Pakiz, \& Heath, 2017; Spaccarotella et al., 2008; Tindall et al., 2019), Republic of Korea (Hwang et al., 2019), Australia (Ndanuko, Tapsell, Charlton, Neale, \& Batterham, 2018), Iran (Fatahi, Haghighatdoost, Larijani, \& Azadbakht, 2019; Nezhad, Aghasadeghi, Hakimi, Yarmohammadi, \& Nikaein, 2016), United Kingdom (Din et al., 2011), Spain (Olmedilla-Alonso et al., 2008; Ros et al., 2004; Sanchis et al., 2019), Chine (Wu et al., 2010), and New Zealand (Mukuddem-Petersen, Stonehouse Oosthuizen, Jerling, Hanekom, \& White, 2007). The follow-up period ranged from 4 weeks to 2 years. Daily recommended amount of walnut intake varied between 6 and $108 \mathrm{~g}$. All trials were done on both gender except for two studies, one including only men (Din et al., 2011) and the other women (Fatahi et al., 2019). The sample of the trials ranged from 21 to 636 subjects. Participants were patients with metabolic syndrome $(n=3)$, chronic kidney disease (CKD) $(n=1)$, diabetes or at high risk for diabetes $(n=4)$, adults at risk for cardiovascular disease and moderate hypercholesterolemia $(n=4)$, and healthy subjects $(n=6)$. Characteristics of included studies are summarized in Table 1. Methodological quality and risk of bias are displayed in Table S1, with most publications having adequate quality for key domains. Taken together, six studies have fair quality, three have poor quality, and eight have good quality.

\section{3 | Meta-analysis results}

\subsection{1 | Effect of walnut intake on SBP}

Eighteen studies, including a total of 1,799 participants (walnut group $=917$ and control $=882$ ), reported SBP as an outcome. Overall results from the random-effects model indicated that walnut intake did not result significant change in SBP (WMD: $0.078 \mathrm{mmHg}, 95 \% \mathrm{Cl}$ : $-0.691,0.848, p=.842$ ), with significant heterogeneity being present among the studies $\left(I^{2}=85.1 \%, p=.000\right)$ (Figure 2$)$. In subgroup analysis, we found that healthy status significantly contributed to the heterogeneity score. Moreover, the effect of walnut intake on SBP was significant in subjects with metabolic syndrome (WMD: $-1.06 \mathrm{mmHg}$; 95\% Cl: $\left.-1.41,-0.72, p<.001 ; l^{2}=72 \%\right)$ and in healthy population (WMD: $-1.29 \mathrm{mmHg} ; 95 \% \mathrm{Cl}:-1.42,-1.16, p<.001 ; l^{2}=63 \%$ ), while it was not significant in patients with type 2 diabetes (WMD: $0.05 \mathrm{mmHg}$; 95\% Cl: $-1.03,1.13, p=.927 ; l^{2}=92 \%$ ) and

TABLE 1 Characteristics of included studies

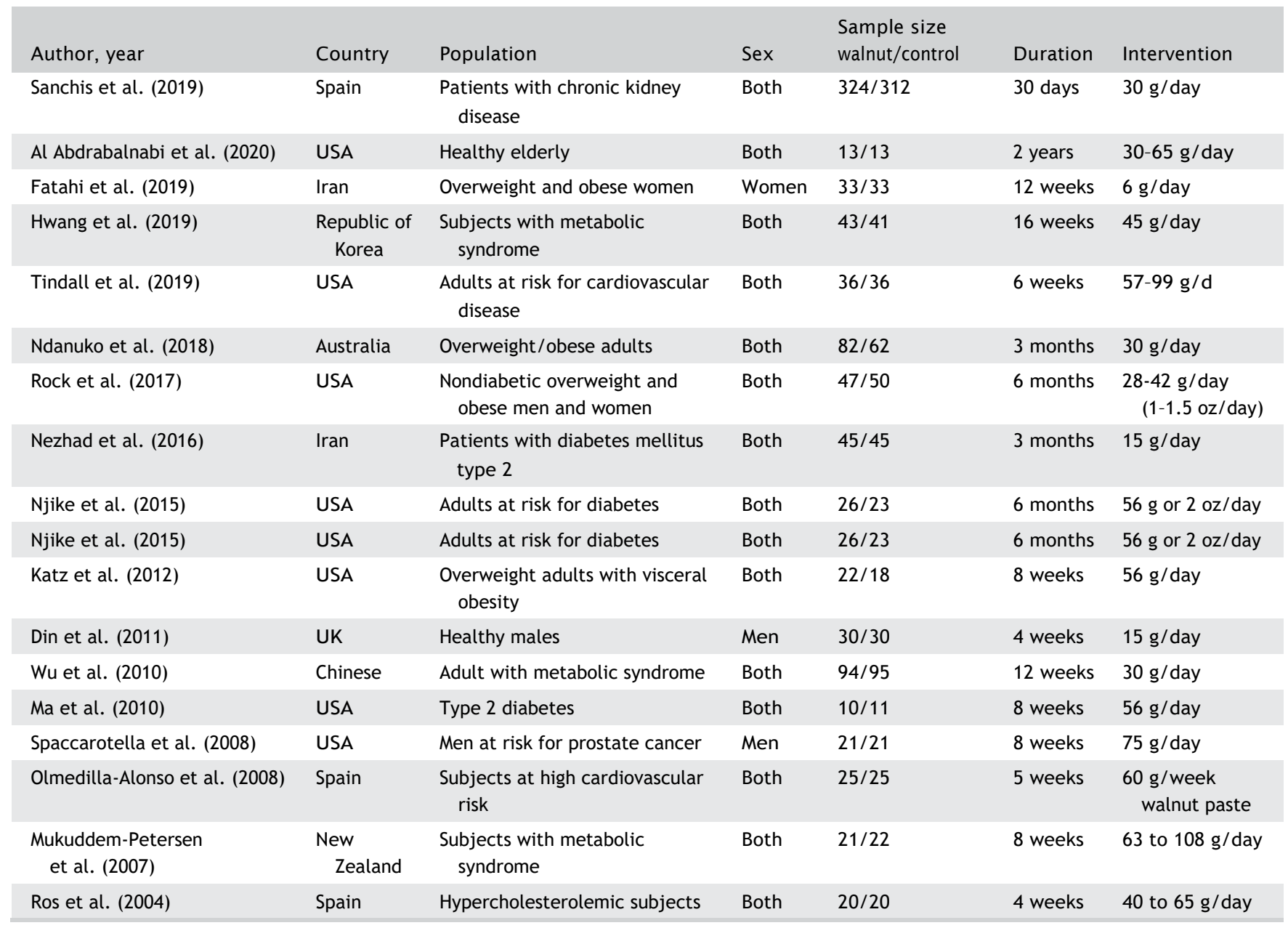




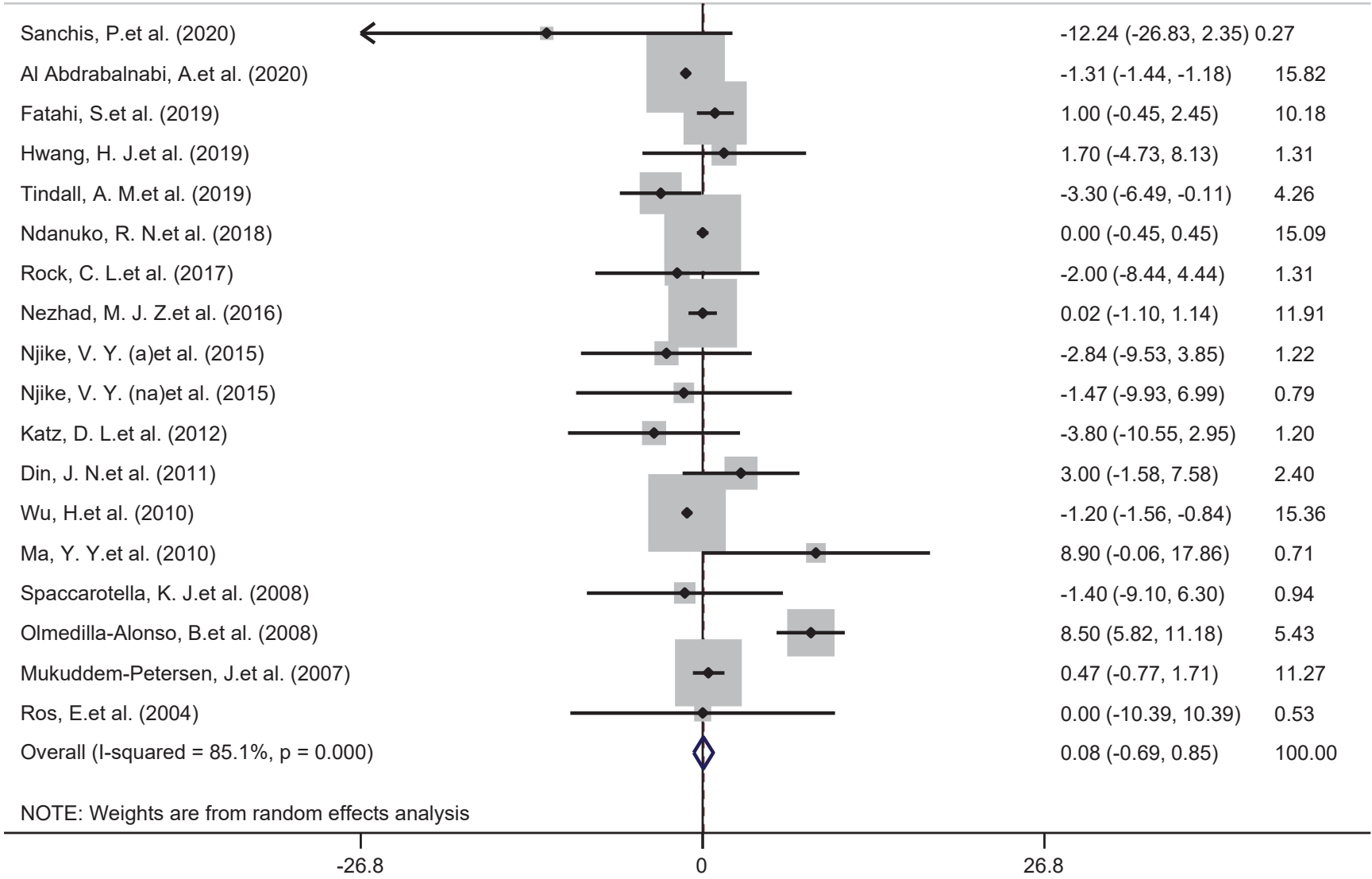

FIG URE 2 Forest plot of randomized controlled trials that investigated the effects of walnut intake on systolic blood pressure (SBP) [Colour figure can be viewed at wileyonlinelibrary.com]

cardiovascular disease (WMD: $0.16 \mathrm{mmHg} ; 95 \% \mathrm{Cl}:-0.27,0.60$, $\left.p=.464 ; l^{2}=34 \%\right)$. There was a greater significant reduction in SBP for studies with walnut intake $>40 \mathrm{~g} /$ day (WMD: $-1.29 \mathrm{mmHg}, 95 \%$ $\mathrm{Cl}:-1.49,-1.16, p<.001 ; l^{2}=43 \%$ ) when compared to $\leq 40 \mathrm{~g} /$ day (WMD: $-0.53 \mathrm{mmHg}, 95 \% \mathrm{Cl}:-0.80,-0.27, p<.001 ; l^{2}=90 \%$ ).

Moreover, the length of intervention $\geq 8$ weeks was linked to a significant reduction in SBP (WMD: $-1.18 \mathrm{mmHg}, 95 \% \mathrm{Cl}:-1.30,-1.06$, $\left.p<.001 ; l^{2}=82 \%\right)($ Table S2).

\subsection{2 | Effect of walnut intake on DBP}

Similar to SBP, 18 studies including a total of 1,799 participants (walnut group $=917$ or control $=882$ ) reported DBP as an outcome. Combined results from the random-effects model indicated that DBP did not change significantly following walnut intake (WMD: $0.08 \mathrm{mmHg}$, $95 \% \mathrm{Cl}:-0.25,0.42, p=.631$ ), with low heterogeneity being present among the studies $\left(l^{2}=35.0 \%, p=.072\right)$ (Figure 3$)$. In subgroup analysis, we found that healthy status, walnut daily dose and treatment duration significantly contributed to the heterogeneity score. Moreover, the effect of walnut intake on DBP was significant in subjects with metabolic syndrome (WMD: $0.22 \mathrm{mmHg} ; 95 \% \mathrm{Cl}$ : 0.02, 0.42, $p=.029 ; l^{2}=36.4 \%$ ) and with cardiovascular disease (WMD: $0.33 \mathrm{mmHg}$; $95 \% \mathrm{Cl}: 0.02,0.65, p=.033 ; l^{2}=0.0 \%$ ), whereas it was not significant in patients with type 2 diabetes ((WMD: $0.36 \mathrm{mmHg}$; 95\% Cl: $1.06,1.79, p=.619 ; l^{2}=79 \%$ ) and healthy subjects (WMD: $-0.12 \mathrm{mmHg}$; 95\% Cl: $-0.51,0.27, p=.537 ; l^{2}=0.0 \%$ ). In addition, there was a significantly more decrease in DBP for studies with walnut intake $\leq 40 \mathrm{~g} /$ day (WMD: $-0.19 \mathrm{mmHg}, 95 \% \mathrm{Cl}:-0.348,-0.034$, $p=.017 ; l^{2}=55 \%$ ) when compared to $>40 \mathrm{~g} /$ day (WMD: $0.32 \mathrm{mmHg}$, $\left.95 \% \mathrm{Cl}:-0.54,1.19, p=.467 ; l^{2}=13.9 \%\right)$. The length of intervention $\geq 8$ weeks significantly resulted in increased DBP (WMD: $0.22 \mathrm{mmHg}$, 95\% Cl: 0.06, 0.38, $p=.005 ; l^{2}=10 \%$ ) (Table S2).

\subsection{3 | Nonlinear dose-response between dose and duration of walnut consumption and BP}

Following dose-response evaluation, walnut intake significantly changed SBP $(p=.015)$ and $\operatorname{DBP}(p=.026)$ through a nonlinear fashion at walnut dose up to $40 \mathrm{~g} /$ day. Based on treatment duration, DBP $(p=.029)$ significantly reduced as well (Figure 4$)$. 


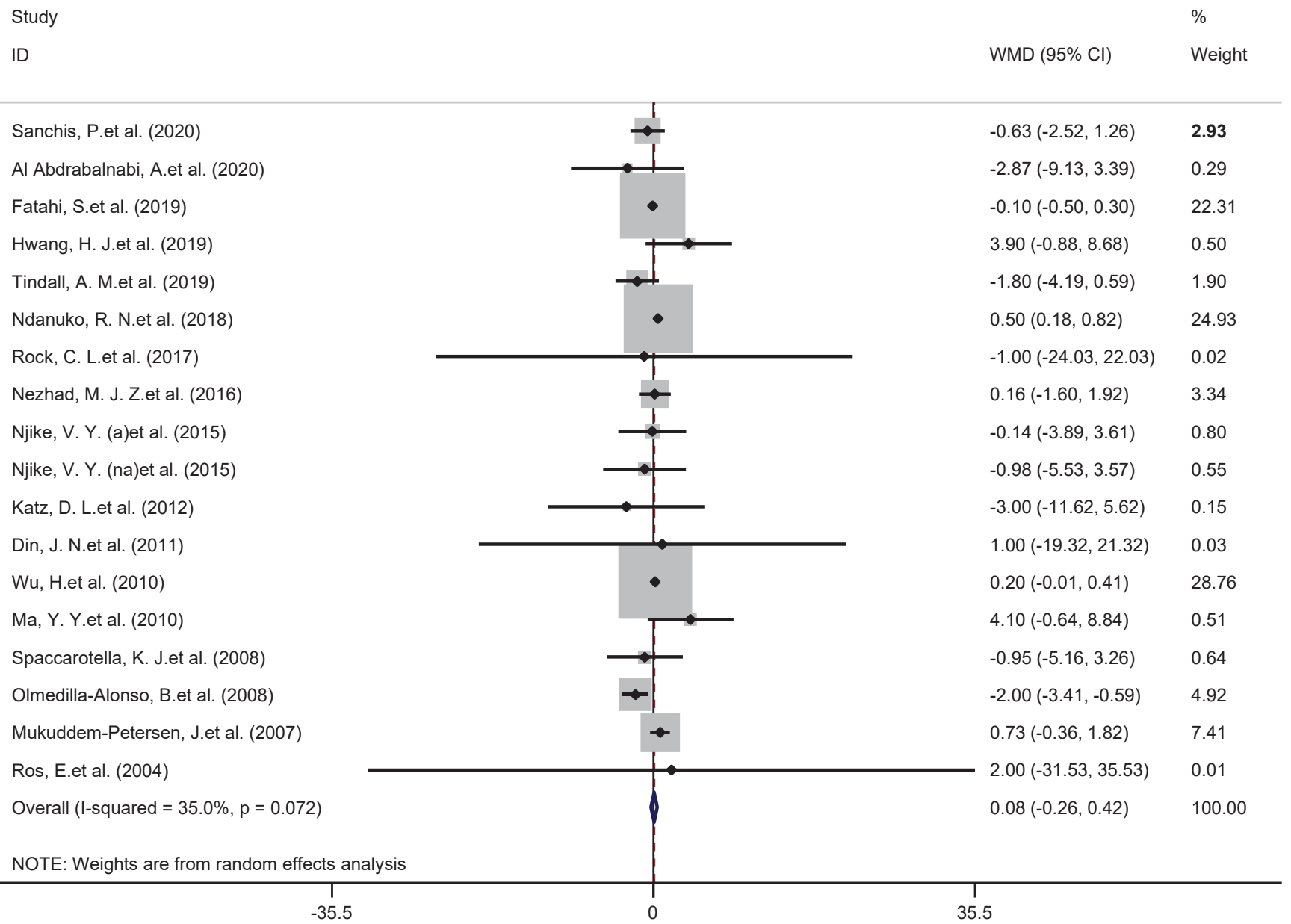

FIG URE 3 Forest plot of randomized controlled trials that investigated the effects of walnut intake on diastolic blood pressure (DBP) [Colour figure can be viewed at wileyonlinelibrary.com]

\subsection{4 | Sensitivity analysis}

To discover the impact of each single study on the combined effect size, we removed each trial from the analysis, step-by-step. We observed no significant effect of any individual study on the combined effect sizes for SBP and DBP (Figure S1).

\subsection{5 | Publication bias}

Evaluation of publication bias by visual inspection of funnel plot not detected publication bias in the meta-analysis for walnut consumption on SBP and DBP values (Figure 5).

\section{4 | DISCUSSION}

Viewed collectively, this meta-analysis did not support walnut consumption, per se, as a BP-lowering strategy. This finding is in line with results of a previous meta-analysis published by Guasch-Ferre et al., who through 26 trials also demonstrated that walnut-rich diet did not lead to significant reduction in both SBP and DBP (Guasch-Ferre, Li, $\mathrm{Hu}$, Salas-Salvado, \& Tobias, 2018). Our meta-analysis provides a most updated result, since we included five studies after the year that the Guasch-Ferre et al' work was published.

Regarding the dosage, we included studies with walnut intake within a range between 6 and $108 \mathrm{~g} /$ day for 4 weeks to 2 years. In subgroup analyses, walnut ingestion $\leq 40 \mathrm{~g}$ was statistically correlated to reduction in SBP (WMD: $-0.53 \mathrm{mmHg}, 95 \% \mathrm{Cl}:-0.79,-0.26$ ) and DBP (WMD: $-0.191 \mathrm{mmHg}, 95 \% \mathrm{Cl}:-0.384,-0.034$ ), and $>40 \mathrm{~g}$ was statistically correlated only to SBP (WMD: $-1.292 \mathrm{mmHg}, 95 \% \mathrm{Cl}$ : $-1.420,-1.164)$. Concerning the treatment duration, $<8$ weeks was statistically correlated to increased SBP (WMD: $1.251 \mathrm{mmHg}, 95 \% \mathrm{Cl}$ : $0.252,2.249$ ) while it did not change for DBP (WMD: $-0.416 \mathrm{mmHg}$, 95\% Cl: -1.139, -0.307). Differently, SBP decreased (WMD: $-1.180 \mathrm{mmHg}, 95 \% \mathrm{Cl}:-1.296,-1.064)$ while DBP increased (WMD: $0.224 \mathrm{mmHg}, 95 \% \mathrm{Cl}: 0.066,0.382$ ) for $\geq 8$ weeks. In other words, both decrease and increase in BP were detected depending on the variable, with paradoxical findings being noted in an attempt to search an ideal cutoff point for daily dose and length of intervention. Altogether, these changes are linked to statistical implication, but when translating into clinical practice the data are modest. For instance, we 
Coef. $=-3.27(95 \%$ CI: $-5.81,-0.73), p=0.015$

Coef. $=0.013(95 \%$ CI: $-0.03,-0.06), p=0.567$
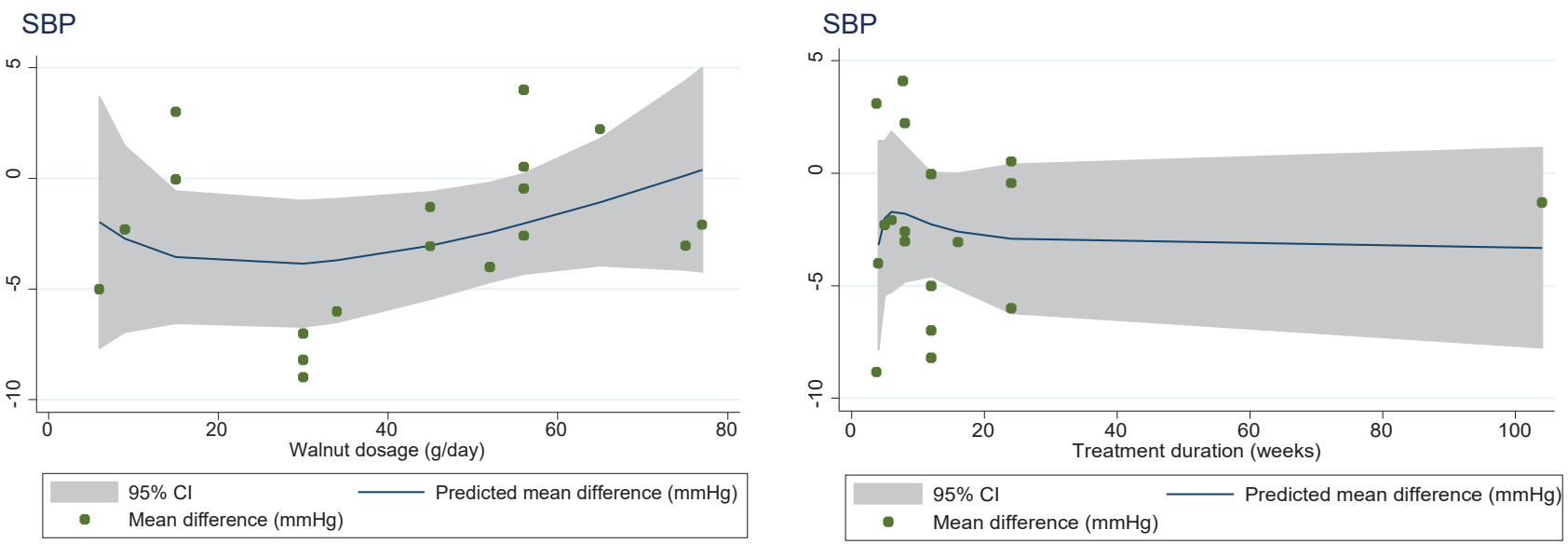

Coef. $=-1.66(95 \%$ CI: $-3.10,-0.22), p=0.026$

Coef. $=-1.83$ ( 95\% CI: $-3.45,-0.21), p=0.029$

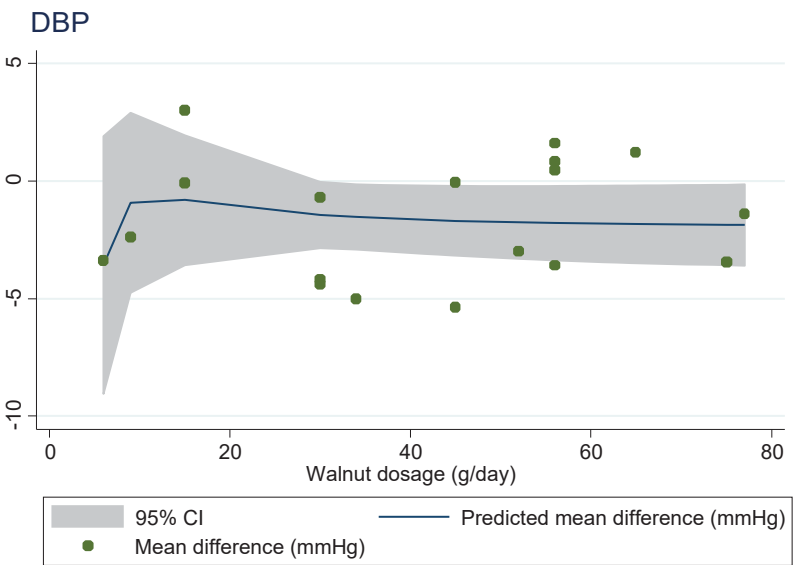
DBP

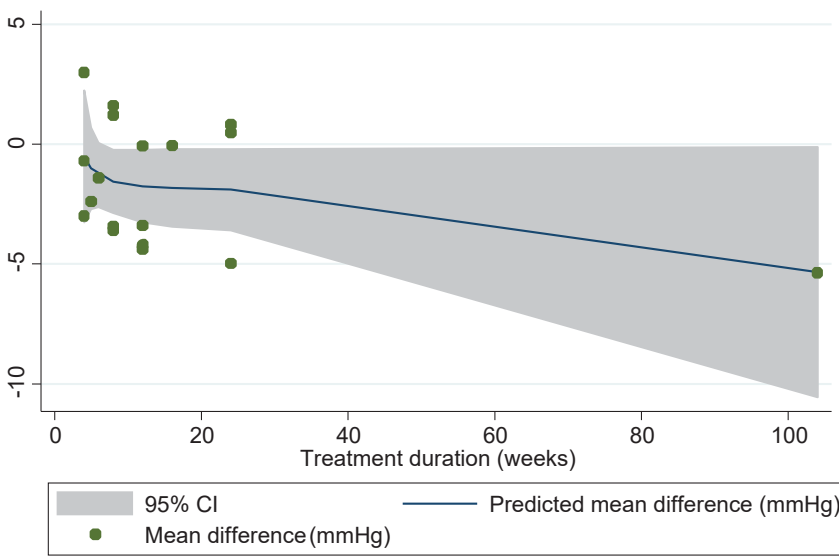

FIG URE 4 Nonlinear dose-responses between walnut consumption and blood pressure (BP) measurements. The $95 \%$ confidence interval $(\mathrm{Cl})$ is depicted in the shaded regions [Colour figure can be viewed at wileyonlinelibrary.com]

(A) $\operatorname{SBP}(p=0.071)$

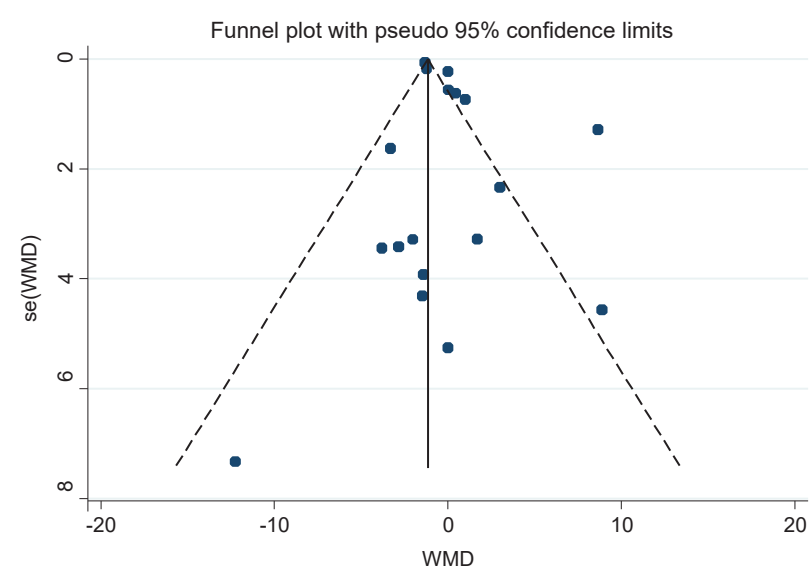

(B) DBP $(\mathrm{p}=0.395)$

Funnel plot with pseudo $95 \%$ confidence limits

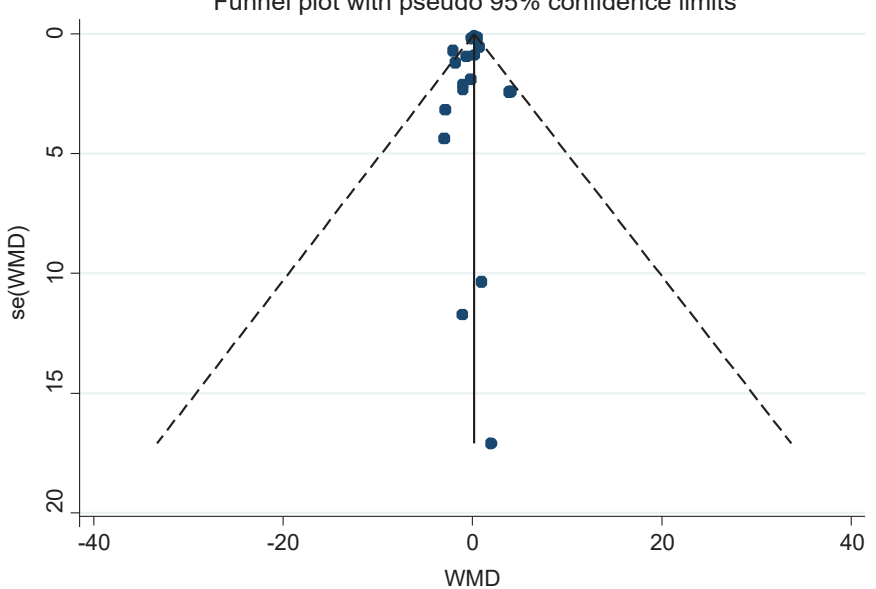

FIG URE 5 Funnel plot of the weighted mean difference (WMD) versus the s.e. of the WMD [Colour figure can be viewed at wileyonlinelibrary.com] 
cannot to draw recommendation based on these sub-analyses because the majority of statistical changes were related to $<1 \mathrm{mmHg}$ of both SBP and DBP, so that a positive or negative alteration of approximately $1 \mathrm{mmHg}$ of BP is a very small clinical difference, especially taking into account the BP categories: $<120 / 80 \mathrm{mmHg}, 120$ $129 /<80 \mathrm{mmHg}, 130-139 / 80-89 \mathrm{mmHg},>140 / 80 \mathrm{mmHg}$, for normal, elevated, stage 1 and stage 2 , respectively; SBP over $180 \mathrm{mmHg}$ and/or DBP over $120 \mathrm{mmHg}$ are classified as hyperten- sive crisis (JACC, 2017). Given that patients with elevated or at stages 1 or 2 of BP categories would be more likely to obtain benefits from nutraceutical strategies, an alteration of $1 \mathrm{mmHg}$ indeed is minimal. Such a variation may occur due to error during the measurement, as the accuracy is determined by the experience and adequate training of the health professional responsible for data collection, as well as by the monitor, whether it is a manual or digital meter. Moreover, followup in nutritional interventions commonly did not employ blinding, once foodstuffs differ from pills. It is therefore important to mention that the lack of blinding is a confounding factor that has not been controlled, which may positively affect the measurement of BP by an individual believe that dietary intervention will improve this parameter or adversely affect BP simply due to the popular white coat syndrome (Pioli, Ritter, de Faria, \& Modolo, 2018).

Not only were the sub-analyses for walnut dosage puzzling, but also for healthy status, which involved patients with cardiometabolic dysregulations and healthy subjects. Correspondingly, decreased SBP was correlated with being healthy (WMD: $-1.290 \mathrm{mmHg}, 95 \% \mathrm{Cl}:-1.418,-1.161)$ and having metabolic syndrome (WMD: $-1.062 \mathrm{mmHg}, 95 \% \mathrm{Cl}:-1.407,-0.718)$. Another paradoxical result was the correlation of increased DBP with patients with metabolic syndrome (WMD: $0.225 \mathrm{mmHg}, 95 \% \mathrm{Cl}$ : $0.023,0.427$ ) and cardiovascular disease (WMD: $0.339 \mathrm{mmHg}, 95 \%$ $\mathrm{Cl}: 0.027,0.651)$. There is no physiological explication for these findings, as an additional dietary-lowering effect is usually more justified in patients with cardiometabolic dysregulation. Despite these inconsistences, in a well-designed trial involving $30-60 \mathrm{~g} /$ day of walnuts, elderly subjects with baseline 24-hr ambulatory SBP $>125 \mathrm{mmHg}$ have a significant decrease of $8.5 \mathrm{mmHg}$ under a 2year follow-up (Domènech et al., 2019). In general, DBP did not change but, most importantly, patients who received walnut needed less antihypertensive medication than controls. Such a SBP decrease of $8.5 \mathrm{mmHg}$ is better than any result obtained by this meta-analysis. Thus, perhaps walnut intake can be an adjuvant dietary tool in the control of hypertension but, ideally, further long-term investigations are imperative, particularly encompassing patients with hypertension and using 24-hr ambulatory BP monitoring, since it is the gold standard for diagnosing this disease (Kinsara, 2017).

Recently, we published another meta-analysis (Fang et al., 2020) by which we did not find positive effect of incorporating walnut into diets to improve anthropometric characteristics used in weight loss monitoring (body weight, body mass index, waist circumference, and fat mass). Thus, coupled with the present finding, this suggests another neutral effect of the walnuts instead of improving clinical proposals. In addition to the lowering-BP effect, some studies also show that nuts intake may be an approach to enhancing weight loss (de Souza, Gomes, de Castro, \& Mota, 2018; Rock et al., 2017), which may ensue in decreased BP as well. At least pertaining to walnuts, our recent meta-analyses did not corroborate shifts in BP and anthropometric characteristics when viewed as a whole.

Although we have already discussed the divergence between statistical and biological data, it is crucial to explain the traditional recommendation for the management of hypertension, as available on guidelines. Upon dietary habits, it should be considered: (a) a healthy eating plain based on vegetables, low-fat dairy products, whole-grain foods, and plant proteins; (b) reducing sodium intake to $2 \mathrm{~g} /$ day (5 $\mathrm{g}$ of salt); (c) increasing dietary potassium intake (e.g., avocado, banana, cocoa powder, and potato); (d) limiting alcohol ingestion to $<2$ drinks per day, whose consumption does not exceed 14 standard drinks per week for men and 9 for women (Nerenberg et al., 2018). Avoiding excessive intake of carbohydrates, particularly sugar, is another nutritional concern in the treatment of hypertension, as the insulin resistance affects blood vessels due to the activation of the cardiovascular tissue renin-angiotensinaldosterone system (Manrique, Lastra, \& Sowers, 2014). Hence, limiting hyper-palatable foods is important, such as traditional food items of cafeteria diets.

Among other nonpharmacological strategies, that is, health behavior management, are: (a) physical exercise: 30-60 min of moderate-intensity dynamic exercise, 4-7 days/ week beyond the routine activities; (b) body weight loss itself; (c) stress management, such as an individualized cognitive-behavioral intervention (Nerenberg et al. , 2018). Regarding pharmacological treatment, as a general rule, the therapy can be based on an individualized strategy, including either monotherapy or combination of: thiazide/thiazide-like diuretic, $\beta$-blocker, angiotensin-converting enzyme inhibitors, and long-acting calcium channel blocker (Nerenberg et al., 2018; Whelton, Carey, \& Aronow, 2018; Whelton, et al., 2018. After these recognizable points, walnuts can be regarded only as an adjuvant foodstuff that putatively may exert some cardiometabolic improvements but without necessarily decreasing BP. Apart from walnuts, other nuts should be considered to allow long-term adherence in clinical practice.

The exact mechanism by which walnut ingestion may improve $\mathrm{BP}$ remains uncertain. Walnuts have relatively high levels of arginine compared to other amino acids (Mapelli, Brambilla, \& Bertani, 2001), which is the precursor amino acid of endogenous vasodilator nitric oxide (NO) (Ros et al., 2004). NO is a potent vasodilator that acts via the second intracellular cyclic guanosine-50-monophosphate (BodeBoger et al., 1996), so that impaired NO bioactivity is implicated in arterial stiffness (Hermann, 2007). Moreover, diminished arginine bioavailability and its increased catabolism are associated with increased cardiovascular risk (Tang, Wang, Cho, Brennan, \& Hazen, 2009). Against all putative effects, $100 \mathrm{~g}$ of walnuts contain approximately $1.5 \mathrm{~g}$ of $\mathrm{l}$-arginine, while the body of evidence favoring the oral arginine supplementation in decreasing BP ranges from 4 to $24 \mathrm{~g} /$ day (Dong et al., 2011). Therefore, the arginine amount in conventional servings of walnuts is not relevant to the clinical context. 
Bearing in mind a nutritional explanation for oleaginous fruits, walnut is highlighted due to its greater amount of total phenols and antioxidant potential (approximately 2,500 mg total phenol and approximately $120 \mu \mathrm{mol}$ trolex eq/g antioxidant capacity in $100 \mathrm{~g}$ of fresh walnut weight) (Abe, Lajolo, \& Genovese, 2010), which are factors that can modulate endothelial cells and hence being conceivable to improve BP. In addition, walnuts are a source of magnesium, potassium and zinc (USDA, 2020), which are well-known minerals with lowering-BP effects, as showed by meta-analyses (Kass, Weekes, \& Carpenter, 2012; Mousavi et al., 2020; Poorolajal et al., 2017). However, the content of zinc and magnesium in walnuts, as well as in any oleaginous fruits, cannot be compared to the effective dosage of these minerals for decreasing BP. For example, $100 \mathrm{~g}$ of walnuts contain $158 \mathrm{mg}$ of magnesium, $441 \mathrm{mg}$ of potassium, $3 \mathrm{mg}$ of zinc (USDA, 2020), which are doses that just complement the daily requirement of these minerals, while the benefits are mainly caused by pharmacological doses. Along these lines, the magnitude of these minerals in improving BP is slight when compared their ingestion across walnuts to elemental doses used in supplementation. Yet, in a common walnut serving (approximately $30 \mathrm{~g}$ ), the amount of magnesium, potassium and zinc drops to 47,132 , and $1 \mathrm{mg}$, respectively. Whereas the principle of nutrition, that is, the long-term adherence together moderate consumption of any food item or nutrient, it is unfeasible to intake a large amount of walnuts or any oleaginous fruits to obtain great doses of minerals. Most importantly, n-3 PUFA intake or its supplementation is a well-studied approach for patients with hypertension (Miller, Van Elswyk, \& Alexander, 2014), and walnuts are a vegetable source of $n-3$ PUFA. Walnuts contain approximately $9 \mathrm{~g}$ of ALA per $100 \mathrm{~g}$, which nutritionally is conceivable to exert physiological and clinical benefits. Accordingly, a Cochrane's meta-analysis (Abdelhamid et al., 2018) of RCTs demonstrated that fish oil supplementation did not lead improvements in primary endpoints (all-cause deaths and cardiovascular events), while sub-analyses for ALA demonstrated some favorable effects in this setting.

It is crucial to highlight that heterogeneity was detected in many sub-analyses. This is a limitation of our study, since heterogeneity reflects a diversity of the studied population whereby influencing our results. On the other hand, we carried out sub-analyses on healthy status and dose-response, and heterogeneity is common among meta-analyses, as the creation of different study designs to answer new questions is a scientific basis. Another limitation is the follow-up period, which ranged from 4 weeks to 2 years and, therefore, longterm effects (i.e., years) of walnut consumption on BP cannot be estimated. Only two included studies were carried out on $a \geq 1$ year follow-up (Al Abdrabalnabi et al., 2020; Sanchis et al., 2019).

As a strong point, this is an updated meta-analysis by which we demonstrate and discuss the mismatch between statistical and biological meaningful, not translating sub-analyses into conclusion to avoid unwarranted applicability in clinical practice. The overall result generated herein is the main finding, that is, neutral or a lack of effects. This is the best and the effortless way to deciphering the message of the present meta-analysis, which also adds importance to the literature, once negative results (i.e., circumstances where the treatment being tested had no effect) are just as essential as positive results. Ultimately, to the best of our knowledge, this is the first meta-analysis of RCTs that examined the dose-response of walnut intake on BP, providing more nuanced guidance for future investigations.

\section{5 | CONCLUSION}

This meta-analysis does not support walnut consumption as a BPlowering strategy. Walnuts can be regarded only as a complementary foodstuff in a healthy eating plan, but without necessarily lowering BP. At best, walnuts are a source of zinc, magnesium, potassium, fiber, antioxidants, and ALA, and are endorsed to be a potential functional food item to improve lipid indices. Among clinical practice, long-term adherence should be considered and, thus, it is conceivable that people use other nuts to obtain more variability.

\section{CONFLICT OF INTEREST}

The authors have no conflicts to declare.

\section{REFERENCES}

Abdelhamid, A. S., Brown, T. J., Brainard, J. S., Biswas, P., Thorpe, G. C., Moore, H. J., ... Song, F. (2018). Omega-3 fatty acids for the primary and secondary prevention of cardiovascular disease. Cochrane Database of Systematic Reviews, 11(11), Cd003177. https:IIdoi.org\10. 1002/14651858.CD003177.pub4.

Abe, L. T., Lajolo, F. M., \& Genovese, M. I. (2010). Comparison of phenol content and antioxidant capacity of nuts. Food Science and Technology, 30, 254-259.

Al Abdrabalnabi, A., Rajaram, S., Bitok, E., Oda, K., Beeson, W. L., Kaur, A., ... Sabate, J. (2020). Effects of supplementing the usual diet with a daily dose of walnuts for two years on metabolic syndrome and its components in an elderly cohort. Nutrients, 12(2), 451. https://doi. org/10.3390/nu12020451

Appel, L. J., Brands, M. W., Daniels, S. R., Karanja, N., Elmer, P. J., \& Sacks, F. M. (2006). Dietary approaches to prevent and treat hypertension: A scientific statement from the American Heart Association. Hypertension, 47(2), 296-308.

Appel, L. J., Moore, T. J., Obarzanek, E., Vollmer, W. M., Svetkey, L. P., Sacks, F. M., ... Windhauser, M. M. (1997). A clinical trial of the effects of dietary patterns on blood pressure. New England Journal of Medicine, 336(16), 1117-1124.

Appel, L. J., Sacks, F. M., Carey, V. J., Obarzanek, E., Swain, J. F., Miller, E. R., ... Laranjo, N. M. (2005). Effects of protein, monounsaturated fat, and carbohydrate intake on blood pressure and serum lipids: Results of the Omni Heart randomized trial. JAMA, 294(19), 24552464.

Banel, D. K., \& Hu, F. B. (2009). Effects of walnut consumption on blood lipids and other cardiovascular risk factors: A meta-analysis and systematic review. The American Journal of Clinical Nutrition, 90 (1), 56-63.

Benjamin, E. J., Blaha, M. J., Chiuve, S. E., Cushman, M., Das, S. R., Deo, R., ... Isasi, C. (2017). Heart disease and stroke statistics-2017 update: A report from the American Heart Association. Circulation, 135(10), e146-e603. 
Bochud, M., Marques-Vidal, P., Burnier, M., \& Paccaud, F. (2011). Dietary salt intake and cardiovascular disease: Summarizing the evidence. Public Health Reviews, 33(2), 530-552.

Bode-Boger, S. M., Boger, R. H., Alfke, H., Heinzel, D., Tsikas, D., Creutzig, A., ... Frolich, J. C. (1996). L-arginine induces nitric oxidedependent vasodilation in patients with critical limb ischemia. A randomized, controlled study. Circulation, 93(1), 85-90. https://doi.org/ 10.1161/01.cir.93.1.85

Challa, H. J., Tadi, P., \& Uppaluri, K. R. (2020). DASH Diet (Dietary Approaches to Stop Hypertension). In StatPearls [Internet], Treasure Island, FL: StatPearls Publishing.

de Souza, R. G. M., Gomes, A. C., de Castro, I. A., \& Mota, J. F. (2018). A baru almond-enriched diet reduces abdominal adiposity and improves high-density lipoprotein concentrations: A randomized, placebocontrolled trial. Nutrition, 55, 154-160.

Del Gobbo, L. C., Falk, M. C., Feldman, R., Lewis, K., \& Mozaffarian, D. (2015). Effects of tree nuts on blood lipids, apolipoproteins, and blood pressure: Systematic review, meta-analysis, and dose-response of 61 controlled intervention trials. The American Journal of Clinical Nutrition, 102(6), 1347-1356. https://doi.org/10.3945/ajcn.115.110965

Din, J. N., Aftab, S. M., Jubb, A. W., Carnegy, F. H., Lyall, K., Sarma, J., ... Flapan, A. D. (2011). Effect of moderate walnut consumption on lipid profile, arterial stiffness and platelet activation in humans. European Journal of Clinical Nutrition, 65(2), 234-239. https://doi.org/10.1038/ ejcn.2010.233

Domènech, M. , Serra-Mir, M., Roth, I., Freitas-Simoes, T., Valls-Pedret, C., Cofán, M., ... Ros, E. (2019). Effect of a walnut diet on office and 24-hour ambulatory blood pressure in elderly individuals. Hypertension (Dallas, Tex.: 1979), 73(5), 1049-1057. https://doi.org/10.1161/ HYPERTENSIONAHA.118.12766

Dong, J. Y., Qin, L. Q., Zhang, Z., Zhao, Y., Wang, J., Arigoni, F., \& Zhang, W. (2011). Effect of oral L-arginine supplementation on blood pressure: A meta-analysis of randomized, double-blind, placebocontrolled trials. American Heart Journal, 162(6), 959-965. https://doi. org/10.1016/j.ahj.2011.09.012

Egan, B. M., Kjeldsen, S. E., Grassi, G., Esler, M., \& Mancia, G. (2019). The global burden of hypertension exceeds 1.4 billion people: Should a systolic blood pressure target below 130 become the universal standard? Journal of Hypertension, 37(6), 1148-1153.

Egger, M., Smith, G. D., Schneider, M., \& Minder, C. (1997). Bias in metaanalysis detected by a simple, graphical test. BMJ, 315(7109), 629-634.

Fan, J. (2018). Local polynomial modelling and its applications: monographs on statistics and applied probability 66, Milton Park, Abingdon, Oxfordshire: Routledge.

Fang, Z., Dang, M., Zhang, W., Wang, Y., Kord-Varkaneh, H., NazaryVannani, A., ... Yang, Y. (2020). Effects of walnut intakeon anthropometric characteristics: A systematic review and dose-response meta-analysis of randomized controlled trials. Complementary Therapies in Medicine, 50, 102395. https://doi.org/10.1016/j.ctim.2020.102395

Fatahi, S., Haghighatdoost, F., Larijani, B., \& Azadbakht, L. (2019). Effect of weight reduction diets containing fish, walnut or fish plus walnut on cardiovascular risk factors in overweight and obese women. Archives of Iranian Medicine, 22(10), 574-583.

Forouzanfar, M. H., Afshin, A., Alexander, L. T., Anderson, H. R., Bhutta, Z. A., Biryukov, S., ... Charlson, F. J. (2016). Global, regional, and national comparative risk assessment of 79 behavioural, environmental and occupational, and metabolic risks or clusters of risks, 1990-2015: A systematic analysis for the Global Burden of Disease Study 2015. The Lancet, 388(10053), 1659-1724.

Forouzanfar, M. H., Liu, P., Roth, G. A., Ng, M., Biryukov, S., Marczak, L., ,... Akinyemiju, T. F. (2017). Global burden of hypertension and systolic blood pressure of at least 110 to $115 \mathrm{mmHg}, 1990-2015$. JAMA, 317 (2), 165-182.

Guasch-Ferre, M., Li, J., Hu, F. B., Salas-Salvado, J., \& Tobias, D. K. (2018). Effects of walnut consumption on blood lipids and other cardiovascular risk factors: An updated meta-analysis and systematic review of controlled trials. The American Journal of Clinical Nutrition, 108(1), 174-187. https://doi.org/10.1093/ajcn/nqy091

Hermann, M. F., Andreas; Luscher, Thomas. (2007). Nitric oxide in hypertension. The Journal of Clinical Hypertension, 8(s12), 17-29.

Higgins, J. (2011). GSe. Cochrane handbook for systematic reviews of interventions version, $5(0)$.

Hozo, S. P., Djulbegovic, B., \& Hozo, I. (2005). Estimating the mean and variance from the median, range, and the size of a sample. BMC Medical Research Methodology, 5(1), 13.

Hwang, H. J., Liu, Y., Kim, H. S., Lee, H., Lim, Y., \& Park, H. (2019). Daily walnut intake improves metabolic syndrome status and increases circulating adiponectin levels: Randomized controlled crossover trial. Nutrition Research and Practice, 13(2), 105-114. https://doi.org/10. 4162/nrp.2019.13.2.105

JACC, (2017). New ACC/AHA high blood pressure guidelines lower definition of hypertension. Washington, DC: Journal of the American College of Cardiology.

Kass, L., Weekes, J., \& Carpenter, L. (2012). Effect of magnesium supplementation on blood pressure: A meta-analysis. European Journal of Clinical Nutrition, 66(4), 411-418. https: //doi.org/10.1038/ejcn.2012.4

Katz, D. L., Davidhi, A., Ma, Y., Kavak, Y., Bifulco, L., \& Njike, V. Y. (2012). Effects of walnuts on endothelial function in overweight adults with visceral obesity: A randomized, controlled, crossover trial. Journal of the American College of Nutrition, 31(6), 415-423. https://doi.org/10. $1080 / 07315724.2012 .10720468$

Kinsara, A. J. (2017). Ambulatory blood pressure monitoring in daily practice. Indian Heart Journal, 69(6), 788-789. https://doi.org/10.1016/j. inj.2017.09.223

Kris-Etherton, P. M., Hu, F. B., Ros, E., \& Sabaté, J. (2008). The role of tree nuts and peanuts in the prevention of coronary heart disease: Multiple potential mechanisms. The Journal of Nutrition, 138(9), 1746S-1751S.

Lawes, C. M., Vander Hoorn, S., \& Rodgers, A. (2008). Global burden of blood-pressure-related disease, 2001. The Lancet, 371(9623), 1513-1518.

Li, L., Tsao, R., Yang, R., Kramer, J. K. \& Hernandez, M. (2007). Fatty acid profiles, tocopherol contents, and antioxidant activities of heartnut (Juglans ailanthifolia Var. cordiformis) and Persian walnut (Juglans regia L.). Journal of Agricultural and Food Chemistry, 55(4), 1164-1169.

Ma, Y. Y., Njike, V. Y., Millet, J., Dutta, S., Doughty, K., Treu, J. A., \& Katz, D. L. (2010). Effects of walnut consumption on endothelial function in type 2 diabetic subjects-A randomized controlled crossover trial. Diabetes Care, 33(2), 227-232. https://doi.org/10.2337/dc091156

Manrique, C., Lastra, G. , \& Sowers, J. R. (2014). New insights into insulin action and resistance in the vasculature. Annals of the New York Academy of Sciences, 1311(1), 138.

Mapelli, S., Brambilla, I., \& Bertani, A. (2001). Free amino acids in walnut kernels and young seedlings. Tree Physiology, 21(17), 1299-1302. https://doi.org/10.1093/treephys/21.17.1299

Mejia, S. B., Kendall, C. W., Viguiliouk, E., Augustin, L. S., Ha, V., Cozma, A. I., ... Leiter, L. A. (2014). Effect of tree nuts on metabolic syndrome criteria: A systematic review and meta-analysis of randomised controlled trials. BMJ Open, 4(7), e004660.

Miller, P. E., Van Elswyk, M., \& Alexander, D. D. (2014). Long-chain omega-3 fatty acids eicosapentaenoic acid and docosahexaenoic acid and blood pressure: A meta-analysis of randomized controlled trials. American Journal of Hypertension, 27(7), 885-896.

Moher, D., Liberati, A., Tetzlaff, J., Altman, D. G., \& Group, P. (2009). Reprint-Preferred reporting items for systematic reviews and metaanalyses: The PRISMA statement. Physical Therapy, 89(9), 873-880.

Morgan, J., Horton, K., Reese, D., Carey, C., Walker, K., \& Capuzzi, D. (2002). Effects of walnut consumption as part of a low-fat, lowcholesterol diet on serum cardiovascular risk factors. International Journal for Vitamin and Nutrition Research, 72(5), 341-347. 
Mousavi, S. M., Mofrad, M. D., do Nascimento, I. J. B., Milajerdi, A., Mokhtari, T., \& Esmaillzadeh, A. (2020). The effect of zinc supplementation on blood pressure: A systematic review and dose-response meta-analysis of randomized-controlled trials. European Journal of Nutrition. https://doi.org/10.1007/s00394-020-02204-5. [Epub ahead of print]

Mukuddem-Petersen, J., Stonehouse Oosthuizen, W., Jerling, J. C., Hanekom, S. M., \& White, Z. (2007). Effects of a high walnut and high cashew nut diet on selected markers of the metabolic syndrome: A controlled feeding trial. British Journal of Nutrition, 97(6), 1144-1153. https://doi.org/10.1017/S0007114507682944

Ndanuko, R. N., Tapsell, L. C., Charlton, K. E., Neale, E. P., \& Batterham, M. J. (2018). Effect of individualised dietary advice for weight loss supplemented with walnuts on blood pressure: The HealthTrack study. European Journal of Clinical Nutrition, 72(6), 894903. https://doi.org/10.1038/s41430-018-0123-0

Nerenberg, K. A., Zarnke, K. B., Leung, A. A., Dasgupta, K., Butalia, S., McBrien, K., ... Gelfer, M. (2018). Hypertension Canada's 2018 guidelines for diagnosis, risk assessment, prevention, and treatment of hypertension in adults and children. Canadian Journal of Cardiology, 34 (5), 506-525.

Nezhad, M. J. Z., Aghasadeghi, K., Hakimi, H., Yarmohammadi, H., \& Nikaein, F. (2016). The effect of walnut oil consumption on blood sugar in patients with diabetes mellitus type 2. International Journal of Endocrinology and Metabolism, 14(3), e34889. https://doi.org/10. 5812/ijem. 34889

NIH. (2018). DASH ranked Best Diet Overall for eighth year in a row by U.S. News and World Report, United States: National Institutes of Health (NIH).

Njike, V. Y., Ayettey, R., Petraro, P., Treu, J. A. , \& Katz, D. L. (2015). Walnut ingestion in adults at risk for diabetes: Effects on body composition, diet quality, and cardiac risk measures. BMJ Open Diabetes Research \& Care, 3(1), e000115. https://doi.org/10.1136/bmjdrc-2015-000115

Olmedilla-Alonso, B., Granado-Lorencio, F., Herrero-Barbudo, C., BlancoNavarro, I., Blázquez-García, S., \& Pérez-Sacristán, B. (2008). Consumption of restructured meat products with added walnuts has a cholesterol-lowering effect in subjects at high cardiovascular risk: A randomised, crossover, placebo-controlled study. Journal of the American College of Nutrition, 27(2), 342-348. https://doi.org/10.1080/ 07315724.2008.10719710

Orsavova, J., Misurcova, L., Ambrozova, J., Vicha, R., \& Mlcek, J. (2015). Fatty acids composition of vegetable oils and its contribution to dietary energy intake and dependence of cardiovascular mortality on dietary intake of fatty acids. International Journal of Molecular Sciences, 16 (6), 12871-12890.

Pioli, M. R., Ritter, A. M., de Faria, A. P., \& Modolo, R. (2018). White coat syndrome and its variations: Differences and clinical impact. Integrated Blood Pressure Control, 11, 73-79. https://doi.org/10.2147/IBPC. S152761

Poorolajal, J., Zeraati, F., Soltanian, A. R., Sheikh, V., Hooshmand, E., \& Maleki, A. (2017). Oral potassium supplementation for management of essential hypertension: A meta-analysis of randomized controlled trials. PLoS One, 12(4), e0174967. https://doi.org/10.1371/journal.pone. 0174967

Rock, C. L., Flatt, S. W., Barkai, H.-S., Pakiz, B., \& Heath, D. D. (2017). Walnut consumption in a weight reduction intervention: Effects on body weight, biological measures, blood pressure and satiety. Nutrition Journal, 16(1), 76. https://doi.org/10.1186/s12937-017-0304-z

Ros, E., Núñez, I., Pérez-Heras, A., Serra, M., Gilabert, R., Casals, E., \& Deulofeu, R. (2004). A walnut diet improves endothelial function in hypercholesterolemic subjects: A randomized crossover trial. Circulation, 109(13), 1609-1614. https://doi.org/10.1161/01.CIR. 0000124477.91474.FF

Sanchis, P., Molina, M. , Berga, F., Muñoz, E., Fortuny, R., Costa-Bauzá, A., ... Buades, J. M. (2019). A pilot randomized crossover trial assessing the safety and short-term effects of walnut consumption by patients with chronic kidney disease. Nutrients, 12(1), 63. https://doi.org/10. 3390/nu12010063

Souza, R. G., Gomes, A. C., Naves, M. M., \& Mota, J. F. (2015). Nuts and legume seeds for cardiovascular risk reduction: Scientific evidence and mechanisms of action. Nutrition Reviews, 73(6), 335-347.

Spaccarotella, K. J., Kris-Etherton, P. M., Stone, W. L., Bagshaw, D. M., Fishell, V. K., West, S. G., ... Hartman, T. J. (2008). The effect of walnut intake on factors related to prostate and vascular health in older men. Nutrition Journal, 7(1), 13. https://doi.org/10.1186/1475-2891-7-13

Tang, W. H., Wang, Z., Cho, L., Brennan, D. M., \& Hazen, S. L. (2009). Diminished global arginine bioavailability and increased arginine catabolism as metabolic profile of increased cardiovascular risk. Journal of the American College of Cardiology, 53(22), 2061-2067. https://doi. org/10.1016/j.jacc.2009.02.036S0735-1097(09)00845-6

Tindall, A. M., Petersen, K. S., Skulas-Ray, A. C., Richter, C. K., Proctor, D. N., \& Kris-Etherton, P. M. (2019). Replacing saturated fat with walnuts or vegetable oils improves central blood pressure and serum lipids in adults at risk for cardiovascular disease: A randomized controlled-feeding trial. Journal of the American Heart Association, 8(9), e011512. https://doi.org/10.1161/JAHA.118.011512

USDA. (2020). https://fdc.nal.usda.gov/fdc-app.html\#/food-details/ $784410 /$ nutrients.

Whelton, P. K., Carey, R. M., \& Aronow, W. S. (2018). Acc/aha/aapa/abc/acpm/ags/APhA/ASH/ASPC/nma/pcna guideline for the prevention, detection, evaluation, and management of high blood pressure in adults: a Report of the American College of Cardiology/American heart Association. Task Force on clinical practice guidelines. Journal of the American College of Cardiology, 71(19), 21992269. https://doi.org/10.1016/j.jacc.2017.11.005.

Whelton, P. K., Carey, R. M., Aronow, W. S., Casey, D. E., Jr., Collins, K. J., Dennison Himmelfarb, C., ... Wright, J. T., Jr. (2018). 2017 ACC/AHA/AAPA/ABC/ACPM/AGS/APhA/ASH/ASPC/NMA/PCNA guideline for the prevention, detection, evaluation, and management of high blood pressure in adults: executive summary: A report of the American College of Cardiology/American Heart Association Task Force on clinical practice guidelines. Circulation, 138(17), e426-e483. https://doi. org/10.1161/cir.0000000000000597

Whelton, P. K., He, J., Appel, L. J., Cutler, J. A., Havas, S., Kotchen, T. A., ,... Winston, M. C. (2002). Primary prevention of hypertension: Clinical and public health advisory from the National High Blood Pressure Education Program. JAMA, 288(15), 1882-1888.

Wu, H., Pan, A., Yu, Z., Qi, B., Lu, L., Zhang, G., ... Lin, X. (2010). Lifestyle counseling and supplementation with flaxseed or walnuts influence the management of metabolic syndrome. Journal of Nutrition, 140(11), 1937-1942. https://doi.org/10.3945/jn.110.126300

Wu, L., Piotrowski, K., Rau, T., Waldmann, E., Broedl, U. C., Demmelmair, H., ... Mantzoros, C. S. (2014). Walnut-enriched diet reduces fasting non-HDL-cholesterol and apolipoprotein $B$ in healthy Caucasian subjects: A randomized controlled cross-over clinical trial. Metabolism, 63(3), 382-391. 